\title{
Prevalence of Smoking among Physicians of Different Specialties in Riyadh, Saudi Arabia: A Cross-Sectional Study
}

\author{
Abeer S Al Shahrani* \\ College of Medicine, Princess Nourah Bint Abdulrahman University, Saudi Arabia
}

\begin{abstract}
Background: Smoking is a significant public health problem worldwide. In Saudi Arabia, smoking prevalence has increased in the last couple of years. Few published studies have assessed the magnitude of this problem among physicians and the factors affecting it.
\end{abstract}

Objectives: This study aims to determine the prevalence of smoking among physicians of different specialties including
medical interns. And to assess the factors affecting smoking habit.

\begin{abstract}
Material and methods: It is cross-sectional study involved physicians working in selected district hospitals in Riyadh. Using a convenient sampling technique, Participants were asked to fill an English, self-administered Questionnaire. Statistical analysis was performed using SPSS statistical software with appropriate statistical tests to assess prevalence and factors associated with smoking.

Results: It involved 287 physicians. Majority of them were Saudi (92.0\%), and $60.3 \%$ of them were males. Their age ranged from 24 to more than 45 years, and half of them (56.6\%) were young. Smokers account for $34 \%$. Male gender was significantly associated with smoking, whereas the presence of smoker among family and friends contribute to smoking habits. Being a resident increases the likelihood of smoking in addition to the number of on-calls. However, no significant association between specialty and smoking status.
\end{abstract}

Conclusions: Smoking is a prevalent problem. Being a male, resident and having a relative or friend who smokes, increases the likelihood of smoking. Efforts should be made to assist and support the physicians to quit smoking.

\section{Keywords}

Factors, Physicians, Prevalence, Smoking, Tobacco

\section{Introduction}

Smoking is considered a significant public health problem worldwide. WHO has estimated that tobacco smoking is the second major cause of death, which is responsible for about six million deaths each year and the fourth most common preventable risk factor for non-communicable diseases. Currently, there are over 1 billion smokers in the world and up to half of them will die prematurely from a tobaccorelated illness [1]. Several strategic and prevention policies were done to combat this growing epidemic [2]. Thus, several studies were conducted to assess \& monitor the prevalence of smoking worldwide.

In the MENA region, one systematic review has found that current or past smoking was $31.2 \%$. It was significantly higher in males (48.0\%) than in females (13.8\%) [3]. In Saudi Arabia, smoking ranges from $2.4-52.3 \%$. This varies according to gender \& age group [4]. One review has shown that prevalence almost doubled especially in males from $21 \%$ in 1996 to $37 \%$ in 2012 [5]. Other studies reported the prevalence of waterpipe smoking around $8-11 \%$, which was common among students [6].

Although smoking-related diseases are well known, it is still prevalent among healthcare staff [7]. Comparison with other health professionals suggests that fewer physicians smoke when compared to nurses, and sometimes less often than dentists do. The highest prevalence was reported in Central/Eastern Europe (37\%), followed by Africa (29\%), Central and South America (25\%) and Asia (17.5\%) [8] and the lowest rates were in the United States, Australia and the

*Corresponding author: Dr. Abeer S Al Shahrani, Assistant Professor \& Consultant Family Medicine, College of Medicine, Princess Nourah Bint Abdulrahman University, Riyadh, Saudi Arabia

Accepted: January 22, 2019

Published online: January 24, 2019

Citation: Al Shahrani AS (2019) Prevalence of Smoking among Physicians of Different Specialties in Riyadh, Saudi Arabia: A Cross-Sectional Study. Arch Fam Med Gen Pract 3(1):70-75 
United Kingdom [7]. A systematic review has shown a range of $16-34 \%$ of current smokers among physician and pharmacists in Saudi Arabia [4].

Different psychosocial \& lifestyle factors influence smoking habit. Previous studies suggested that peer pressure is the most important factor affecting smoking initiation followed by parents smoking then media [9]. Majority of smokers started at an early age and continued afterward [10]. Work \& workplace have their impact on smoking. It is hypothesized that job strain might influence smoking behavior, with high job strain, high effort-reward imbalance, and high job demands were associated with a higher likelihood of current smoking [11]. On the other hand, no effect was observed with job strain and job demand on either cessation or relapse rates [12]. One study identified that being resident or specialized in anesthesia or surgery will have a higher percentage of smoking [13].

Moreover, shift work is associated with higher smoking rate when compared to non-shift work [14]. The implementation of comprehensive tobacco control measures in the workplace may support smoking abstinence among physicians [15]. Having a $100 \%$ smoke-free workplace reduced smoking prevalence by $6 \%$ and average daily consumption by $14 \%$ relative to workers who were subjected to minimal or no restrictions [16].

Several studies conducted during the last 20 years have shown that the tobacco epidemic is firmly established in the Kingdom of Saudi Arabia. Only a few studies have been investigating the patterns an of smoking among health care professionals in general, and particularly in physicians $[17,18]$. Moreover, few of them explore in-depth the impact of work on smoking consumption among different medical \& surgical specialties. This study aims to determine the prevalence of smoking among physicians of various specialties including interns and to assess factors affecting smoking habit, in specific the work \& lifestyle factors.

\section{Materials and Methods}

\section{Study design}

A cross-sectional study, participants were from a selected number of the district hospital in Riyadh, both governmental \& private hospital. It was conducted over a six-month period in 2017.

It involved physicians from different medical \& surgical specialties as well as medical interns, who are living in Riyadh. Variables including the sociodemographic data, work-related factors, lifestyle factors, smoking prevalence, behavior, and smoking cessation. Participants were asked to fill in an English-language, self-administered questionnaire that was designed based on previous literature $\&$ validated tool such as GHPSS [19]. We have used both electronic \& paper forms.

We have used a convenience sampling technique and calculated the sample size using a statistical software program considering that population size (N): 70000, Hypothesized \% frequency of outcome factor in the population (p): $50 \%+/-$ 5 with a confidence limits as \% of 100 (absolute +/- \%)(d):
$5 \%$, the design effect (for cluster surveys-DEFF): 1 and a $90 \%$ confidence interval with $80 \%$ power, the estimated sample size is 275-300 participants.

\section{Statistics}

Statistical analysis was performed using SPSS statistical software (release 24, SPSS Inc., Chicago, US). We managed missing data using the mean of series responses. However, we have little missing data because we were using the online forms mainly, making it unlikely to have absent answers. The completed questionnaire was checked and pretested for clarity and suitability among 20 individuals. We presented data as frequencies and proportions for categorical data such as education level, marital status, etc., and mean and standard deviation (SD) for continuous data such as age, some working hours and some on-calls. Thus, we used ANOVA (F-test) to compare means of continuous variables in addition to the chi-square test to assess associations between categorical variables. Multivariate logistic regression was conducted to verify demographic/lifestyle/work-related factors that affect smoking habit. A p-value $\leq 0.05$ was considered statistically significant.

\section{Ethics}

This study was conducted by ethical standards. The university's IRB board has approved it. It involves physicians who agreed to participate. They have read, understood and signed a written/online consent form that has been placed on the cover page of the questionnaire. Data are anonymous and will be used for research purposes.

\section{Results}

\section{Characteristics of the study population}

We have distributed 300 surveys, the response rate was $95.7 \%$, it included 290 participants, and three were excluded due to different occupations (nursing \& physiotherapy). The majority of the participants were Saudi (92.0\%) and $60.3 \%$ of them were males. Their age ranged from 24 to more than 45 years, and half of them (56.6\%) were young (in the age group of 24 to 29 years). Regarding participants' occupation, $40.1 \%$ residents, $23 \%$ intern, $22.6 \%$ consultants, $13.9 \%$ registrars. Sixty-six percent of the participants work in Semigovernmental health sectors, and $29.7 \%$ works in the ministry of health (Table 1).

\section{Smoking prevalence}

The prevalence of smoking was $34.1 \%$ among which $23 \%$ of them were smoking tobacco, and $20 \%$ were smoking water pipe (Shisha) as shown in Table 2 . The smoking prevalence for a male is $70.4 \%$ and for a female is $29.6 \%$. Smoking was more prevalent among resident physicians (50\%), followed by the interns with $22.4 \%$ and then the registrars with the percentage of $15.3 \%$ (Table 3 ). However, the smoking habit was more prevalent among participants with medical specialties (32.7\%) as shown in Figure 1. Chi-square's test determined that there was a statistically significant difference in the proportion of smoking participants $\left(X^{2}=11.512\right.$, $p$ value $=0.021$ ). Moreover, for the specialty, the critical value for $X^{2}$ 
Citation: Al Shahrani AS (2019) Prevalence of Smoking among Physicians of Different Specialties in Riyadh, Saudi Arabia: A Cross-Sectional Study. Arch Fam Med Gen Pract 3(1):70-75

Table 1: Characteristics of the participants ( $n=287)$.

\begin{tabular}{|c|c|c|c|}
\hline Variable & No. & Percent \% & Valid Percent \% \\
\hline \multicolumn{4}{|l|}{ Age groups } \\
\hline $24-29$ years & 162 & 56.4 & 56.6 \\
\hline 30 - 35 years & 68 & 23.7 & 23.8 \\
\hline 36 - 40 years & 33 & 11.5 & 11.5 \\
\hline $41-45$ years & 12 & 4.2 & 4.2 \\
\hline More than 45 years & 11 & 3.8 & 3.8 \\
\hline \multicolumn{4}{|l|}{ Gender } \\
\hline Male & 173 & 60.3 & 60.3 \\
\hline Female & 114 & 39.7 & 39.7 \\
\hline \multicolumn{4}{|l|}{ Nationality } \\
\hline Saudi & 264 & 92.0 & 92.0 \\
\hline Non-Saudi & 23 & 8.0 & 8.0 \\
\hline \multicolumn{4}{|l|}{ Occupation } \\
\hline Intern & 66 & 23.0 & 23.0 \\
\hline Resident & 115 & 40.1 & 40.1 \\
\hline Registrar/Specialist & 40 & 13.9 & 13.9 \\
\hline Consultant & 65 & 22.6 & 22.6 \\
\hline Others & 1 & 0.3 & 0.3 \\
\hline \multicolumn{4}{|l|}{ Specialties } \\
\hline Intern & 65 & 22.6 & 22.7 \\
\hline Medical Specialties & 97 & 33.8 & 33.9 \\
\hline Surgical Specialties & 78 & 27.2 & 27.3 \\
\hline Emergency \& Critical care & 38 & 13.2 & 13.3 \\
\hline Basic Sciences \& others & 8 & 2.8 & 2.8 \\
\hline \multicolumn{4}{|l|}{ Health sector } \\
\hline $\mathrm{MOH}$ & 85 & 29.6 & 29.7 \\
\hline Semi-governmental & 190 & 66.2 & 66.4 \\
\hline Private sector & 5 & 1.7 & 1.7 \\
\hline Others & 6 & 2.1 & 2.1 \\
\hline \multicolumn{4}{|l|}{ Average monthly income } \\
\hline less than 10000 SR & 62 & 21.6 & 21.6 \\
\hline $10000-16000$ & 33 & 11.5 & 11.5 \\
\hline $17000-23000$ & 103 & 35.9 & 35.9 \\
\hline $24000-28000$ & 22 & 7.7 & 7.7 \\
\hline $29000-34000$ & 21 & 7.3 & 7.3 \\
\hline More than 34000 & 46 & 16.0 & 16.0 \\
\hline
\end{tabular}

is 2.919 with $p$ value $=0.572$. Therefore, there is no statistical relationship between smoking habit and the specialties of participants.

\section{Factors affecting smoking habit}

Multiple regression was conducted to verify sociodemo-

Table 2: Prevalence of smoking $(n=287)$.

\begin{tabular}{|c|c|c|c|}
\hline Variable & No. & Percent \% & $\begin{array}{l}\text { Valid } \\
\text { Percent \% }\end{array}$ \\
\hline \multicolumn{4}{|l|}{ Smoking prevalence } \\
\hline Nonsmoker & 189 & 65.9 & 65.9 \\
\hline Smoker & 98 & 34.1 & 34.1 \\
\hline \multicolumn{4}{|l|}{ Are you smoking cigarettes (Tobacco)? } \\
\hline I have never smoked tobacco & 195 & 67.9 & 67.9 \\
\hline $\begin{array}{l}\text { I didn't smoke during the past year (Ex- } \\
\text { smoker) }\end{array}$ & 26 & 9.1 & 9.1 \\
\hline Yes & 66 & 23.0 & 23.0 \\
\hline \multicolumn{4}{|l|}{ Are you smoking Water-pipe (Shesha)? } \\
\hline I have never smoked shisha & 200 & 69.7 & 69.7 \\
\hline $\begin{array}{l}\text { I didn't smoke during the past year (Ex- } \\
\text { smoker) }\end{array}$ & 29 & 10.1 & 10.1 \\
\hline Yes & 58 & 20.2 & 20.2 \\
\hline
\end{tabular}

Table 3: Smoking prevalence according to physician's occupation.

\begin{tabular}{|l|l|l|l|l|}
\hline \multirow{2}{*}{ Occupation } & \multicolumn{3}{|l|}{ Smoking habit } & Total \\
\cline { 3 - 4 } & & Nonsmokers & Smokers & \\
\hline Intern & No & 44 & 22 & 66 \\
\hline \multirow{2}{*}{ Resident } & $\%$ & $23.3 \%$ & $22.4 \%$ & $23.0 \%$ \\
\hline \multirow{2}{*}{ Registrar } & No & 66 & 49 & 115 \\
\hline & No & $34.9 \%$ & $50.0 \%$ & $40.1 \%$ \\
\hline Consultant & $\%$ & 25 & 15 & 40 \\
\hline \multirow{2}{*}{ Others } & No & $13.2 \%$ & $15.3 \%$ & $13.9 \%$ \\
\hline \multirow{2}{*}{ Total } & $\%$ & $28.0 \%$ & 12 & 65 \\
\hline & No & 1 & $12.2 \%$ & $22.6 \%$ \\
\hline & No & $0.5 \%$ & 0 & 1 \\
\hline & $\%$ & 189 & $0.0 \%$ & $0.3 \%$ \\
\hline
\end{tabular}

Table 4: Multiple regression coefficient of sociodemographic factors affecting smoking

\begin{tabular}{|c|c|c|c|c|c|c|}
\hline \multicolumn{2}{|l|}{ Statistical indicator } & \multicolumn{5}{|c|}{ Regression coefficients } \\
\hline Excluded variables & \multirow[t]{3}{*}{ Predictive variables } & \multirow{2}{*}{\multicolumn{2}{|c|}{$\begin{array}{l}\text { Unstandardized } \\
\text { Coefficients }\end{array}$}} & \multirow{3}{*}{$\begin{array}{l}\text { Standardized } \\
\text { Coefficients } \\
\text { Beta }\end{array}$} & \multirow[t]{3}{*}{$\mathrm{t}$} & \multirow[t]{3}{*}{ Sig } \\
\hline \multirow{2}{*}{$\begin{array}{l}\text { Sleep } \\
\text { Exercise }\end{array}$} & & & & & & \\
\hline & & B & Std. Error & & & \\
\hline $\begin{array}{l}\text { Daily coffee consumption } \\
\text { Working hours } \\
\text { Age }\end{array}$ & Constant & $-0.513-$ & 0.136 & & -3.766 & $0.000^{* *}$ \\
\hline \multicolumn{7}{|l|}{$\begin{array}{l}\text { Age } \\
\text { Nationality } \\
\text { Occupation }\end{array}$} \\
\hline \multirow{2}{*}{$\begin{array}{l}\text { Specialty } \\
\text { Specialty subgroups } \\
\text { Health sector } \\
\text { Monthly income }\end{array}$} & Presence of smoking among family & 0.210 & 0.053 & 0.221 & 3.952 & $0.000^{* *}$ \\
\hline & Number of on-calls per month & 0.050 & 0.018 & 0.151 & 2.688 & $0.008^{* *}$ \\
\hline
\end{tabular}

$R^{2}=0.131(13.1 \%), F=14.098, P=0.000$

$\mathrm{R}^{2}$ : Square correlation; F for ANOVA; ${ }^{* *}$ significant at 0.01 level; "significant at 0.05 level.

N.B: Predictors: Gender, age, education, occupation and medical problems variables were excluded from the model. 


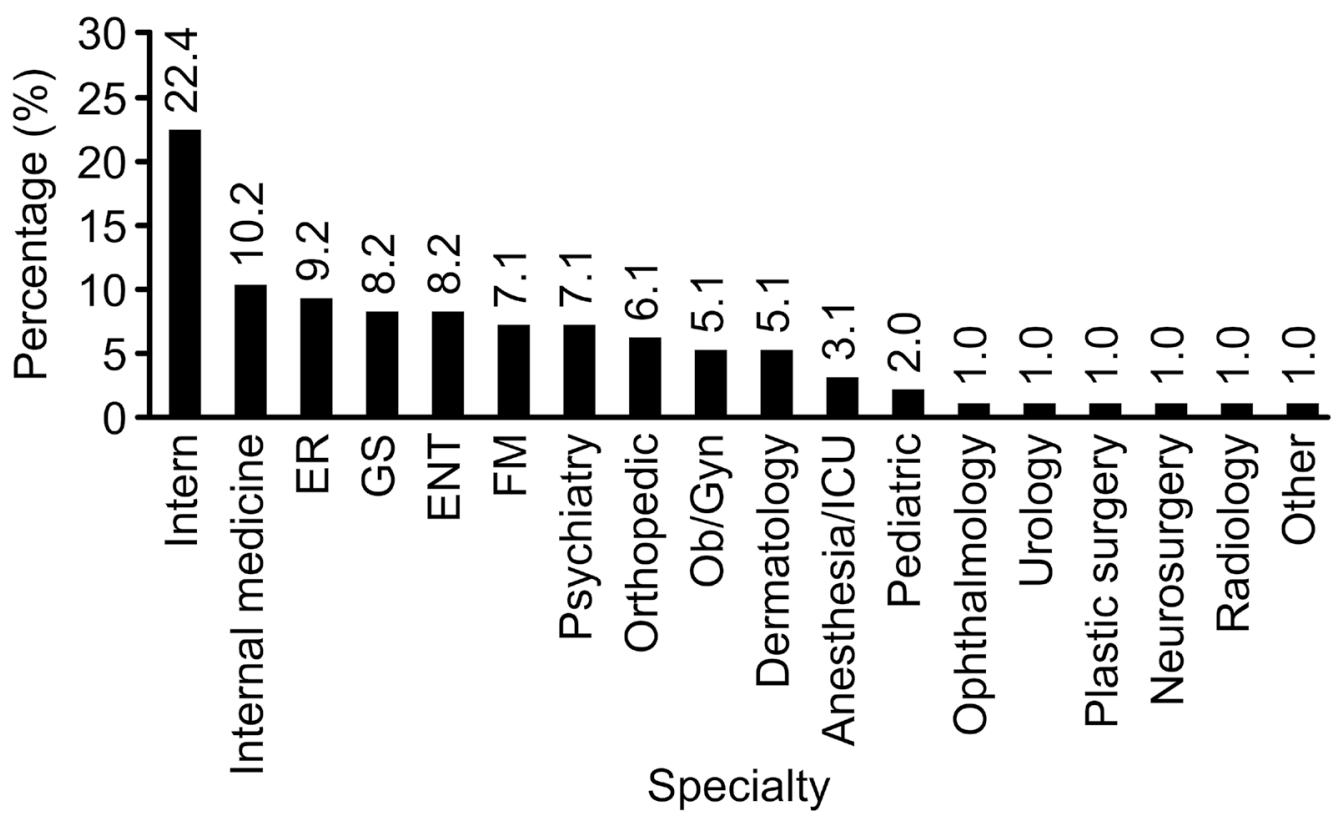

Figure 1: Smoking prevalence among different medical and surgical specialties.

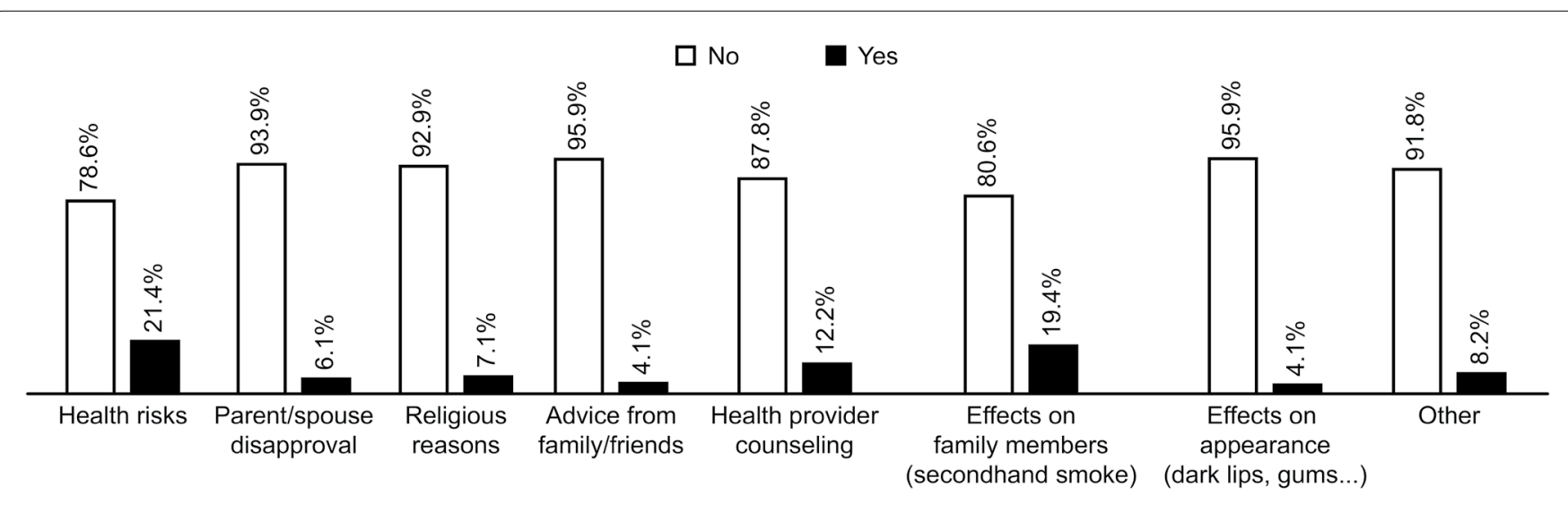

Figure 2: Factors contributing to smoking cessation among current and ex-smokers.

graphic factors that affecting the smoking habit. The results showed that the coefficient of determination $R^{2}$ is equal $=$ $2.2 \%$ and $F$ value $=6.411$ which is statistically significant at level $\mathrm{P}<0.05$ with gender. However, other sociodemographic factors have no statistically significant association with smoking such as age, nationality, monthly income (Table 4).

\section{Smoking cessation and relapse}

It has been showed that health risks and passive smoking $(21.4 \%, 19.4 \%)$ respectively, came as the most important factors that help the smokers to stop smoking. Health providers counseling (12.2\%) also emerge as one of the elements that contribute to smoking cessation (Figure 2). When it comes to methods for smoking cessation, almost onethird of participants (31.6\%) who reported that information on social media/T.V/internet is the best method can be used to quit smoking, followed by healthcare advice \& self-help booklet $(8.2 \% \& 5.1 \%)$ respectively. Regarding the causes of smoking relapse, the most common one was the social stress (24.5\%) followed by withdrawal symptoms (21.4\%).

\section{Discussion}

Based on the general characteristics of the study population the smoking prevalence is $34.1 \%$ among which $23 \%$ of them were smoking tobacco, and $20 \%$ were smoking water pipe (Shisha). This number is relatively high compared to international studies, a review conducted on Japanese physicians showed a decline in smoking prevalence to $16 \%$ among males 5\% among females [20]. Moreover, Estonian physicians showed a lower prevalence compared to their general population [21]. In Saudi Arabia, few published studies assess the smoking pattern among health professionals in general and physicians in specific. One study report a prevalence of $48 \%$ with males significantly more than females [17]. Interestingly, the incidence of waterpipe smoking (Shisha) is higher than reported ones among the general population [6].

It has been found that smoking is more common among the young age group, i.e. interns and residents. This is consistent with the previous findings that smokers start earlier 
in their lives and continues afterward [22]. Multiple studies investigated smoking among medical students showed that majority of them were males began during their college study [9]. Some students thought that smoking could be used as a coping strategy to face stress [23]. Others, smoke for leisure and imitation of other people [24].

The current study is the first published one that investigated the prevalence of smoking among different medical and surgical specialties; also, it explores the possible association of smoking to socio-demographic and works related factors. Being a male and the presence of smoker among family/friends is strongly associated with the smoking habit. This finding is almost consistent with other studies $[13,25]$. Resident physicians are reported to have the highest smoking rate of $50 \%$. This finding might be due to the increased number of participants among residents followed interns and consultant respectively. A similar outcome was reported in another study conducted in the Southern region of Saudi Arabia [25]. The current study did not show an association of smoking with specialty. The probably large sample size that includes an equivalent number of participants from different medical and surgical specialties can prove an association.

The medical profession is a highly demanding field; workers are usually facing challenging situations and shift/ on calls that associated with a considerable amount of stress. Smokers claim that smoking reduces stress [22]. This could explain that the number of on-calls influenced smoking habit. However, other work-related factors showed insignificant influence on the smoking such as practice setting, duration of working hours. In Saudi Arabia, a royal decree in 11/1/1404 $\mathrm{H}$ insisted upon the prohibition of tobacco smoking in different institutions including healthcare facilities. However, implementation varies from one workplace to another [26]. Countries that implement strict tobacco control have a decline in the prevalence of smoking $[15,20]$. However, smokers may compensate for exposure to workplace smoking bans by escaping restrictions [27].

Previous smoking cessation was reported in about $40 \%$ of the smoker for about one month \& $24 \%$ for about 1-5 months. The most frequent factor that influences quitting attempt was the awareness of smoking health risk in addition to the effect of second-hand smoking on their families. One study indicated that all respondents (physicians) agree that smoking is harmful [28]. Moreover, another study reported physician readiness to quit smoking is more than the general population [29]. Other study indicated that successful quitters were less likely to have switched to light cigarettes for health concerns, and more likely to have rules against smoking in their homes, aged 35 years or older, married, and to have at least a college education [30]. In another hand, stress was perceived as a barrier for successful smoking cessation [31]. There is a need for specific strategies to encourage smoking physicians to quit as the majority of them depends on their efforts and utilize media information to assist with smoking cessation.

\section{Conclusion}

Physicians play a significant role in health promotion and prevention. They set very good example for their patients in embracing a healthy lifestyle and avoiding smoking. Despite the awareness of smoking health risks and the presence of tobacco control policies, this study reported a high prevalence of smoking among younger physicians. Researches on a larger scale are required to furtherly explore the attitude and behavior of smoking physicians and whether their work and workplace has an impact on this destructive habit. Also, smoking cessation programs should target medical students and interns as the evidence shown that smokers tend to initiate smoking early in their life.

\section{Acknowledgment}

The authors would like to acknowledge with much appreciation, the input of the Deanship of Scientific Research - Research Service Center, at Princess Nourah Bint Abdulrahman University, for their contribution to data analysis. Special thanks to Dr. Eman Al Shahrani, Department of Family and Community Medicine at King Saud University Medical City for her participation in data collection.

\section{References}

1. World Health Organization (2015) WHO global report on trends in prevalence of tobacco smoking 2015.

2. World Health Organization (2017) Monitoring tobacco use and prevention policies.

3. Khattab A, Javaid A, Iraqi G, et al. (2012) Smoking habits in the Middle East and North Africa: Results of the BREATHE study. Respir Med 106: S16-S24.

4. Bassiony MM (2009) Smoking in Saudi Arabia. Saudi Med J 30: 876-881.

5. Almutairi KM (2015) Trends in current tobacco use, smoking rates and quit attempts among Saudi population during periods of 17 years (1996-2012): Narrative review article. Iran J Public Health 44: 170-175.

6. Akl EA, Gunukula SK, Aleem S, et al. (2011) The prevalence of waterpipe tobacco smoking among the general and specific populations: A systematic review. BMC Public Health 11: 244.

7. Smith DR, Leggat PA (2007) An international review of tobacco smoking in the medical profession: 1974-2004. BMC Public Health 7: 115.

8. Abdullah AS, Stillman FA, Yang L, et al. (2013) Tobacco use and smoking cessation practices among physicians in developing countries: A literature review (1987-2010). Int J Environ Res Public Health 11: 429-455.

9. So Wali (2011) Smoking habits among medical students in Western Saudi Arabia. Saudi Med J 32: 843-848.

10. Almutairi KM (2014) Smoking among Saudi students: A review of risk factors and early intentions of smoking. J Community Health 39: 901-907.

11. Kouvonen A, Kivimäki M, Virtanen M, et al. (2005) Work stress, smoking status, and smoking intensity: An observational study of 46,190 employees. J Epidemiol Community Health 59: 63-69.

12. Rowe DJ, Dunn JR, Muntaner C (2015) The impact of job strain on smoking cessation and relapse in the Canadian population: $\mathrm{A}$ cohort study. J Epidemiol Community Health 69: 931-936.

13. Sotiropoulos A, Gikas A, Spanou E, et al. (2007) Smoking habits and associated factors among Greek physicians. Public Health 


\section{1: $333-340$}

14. Zhao I, Turner C (2008) The impact of shift work on people's daily health habits and adverse health outcomes. Australian Journal of Advanced Nursing 25: 8-22.

15. John U, Hanke M (2003) Tobacco-smoking prevalence among physicians and nurses in countries with different tobacco-contro activities. Eur J Cancer Prev 12: 235-237.

16. Farrelly MC, Evans WN, Sfekas AE (1999) The impact of workplace smoking bans: Results from a national survey. Tob Control 8 : 272-277.

17. AA Saeed (1991) Attitudes and behaviour of physicians towards smoking in Riyadh city, Saudi Arabia. Trop Geogr Med 43: 76-79.

18. S Siddiqui, DO Ogbeide (2001) Profile of smoking amongst health staff in a primary care unit at general hospital in Riyadh, Saud Arabia. Saudi Med J 22: 1101-1104.

19. http://www.who.int/tobacco/surveillance/ghps/en

20. Smith DR, Wada K (2013) Declining Rates of tobacco use in the Japanese medical profession, 1965-2009. J Epidemiol 23: 4-11.

21. Parna K, Rahu K, Rahu M (2005) Smoking habits and attitudes towards smoking among Estonian physicians. Public Health 119 390-399.

22. Abdel Rahim BE, Mahfouz MS, Yagoub U, et al. (2014) Practice and attitude of cigarette smoking: A community-based study. PLoS ONE 9: e92939.

23. Al-Haqwi Al, Tamim H, Asery A (2010) Knowledge, attitude and practice of tobacco smoking by medical students in Riyadh,
Saudi Arabia. Ann Thorac Med 5: 145-148.

24. Al-Kaabba AF, Saeed AA, Abdalla AM, et al. (2011) Prevalence and associated factors of cigarette smoking among medical students at King Fahad Medical City in Riyadh of Saudi Arabia. J Family Community Med 18: 8-12.

25. Mahfouz AA, Shatoor AS, Al-ghamdi BR, et al. (2013) Tobacco use among health care workers in Southwestern Saudi Arabia. BioMed Res Int.

26. Al-Munif M (2009) Report on tobacco control program of Ministry of Health in Saudi Arabia. Ministry of Health Tobacco Control Program.

27. Dunbar MS (2015) Workplace smoking bans and daily smoking patterns: Implications for nicotine maintenance and determinants of smoking in restricted environments.

28. Habadi MI, Alsharief E, Ali A (2015) Smoking prevalence, knowledge, behaviour, and attitudes among physicians working in primary health care centers, in Jeddah, Saudi Arabia. Middle East J Intern Med 5: 3-10.

29. Mansoura FSI, Abdulmalik MA, Salama RE (2010) Profile of smoking among primary healthcare doctors in Doha, Qatar 2007. Qatar Medical Journal 19: 36-42.

30. Lee C, Kahende J (2007) Factors associated with successful smoking cessation in the United States, 2000. Am J Public Health 97: 1503-1509.

31. Pipe A, Sorensen M, Reid R (2009) Physician smoking status, attitudes toward smoking, and cessation advice to patients: An international survey. Patient Educ Couns 74: 118-123. 